\title{
PENGARUH UMUR TANAMAN TERHADAP DIMENSI POHON SENGON (Paraserianthes falcataria. L) PADA KETINGGIAN TEMPAT TUMBUH YANG BERBEDA
}

\author{
ANING MUNIR \\ Program Pascasarjana Universitas Winaya Mukti
}

The Influence of Plant Age to Dimension of Paraserianthes falcataria L at Different Altitude

\section{Diterima 17 Februari 2018/Disetujui 5 Maret 2018}

\begin{abstract}
Sengon (Paraserianthes falcataria) can grow from beach to $1600 \mathrm{~m}$ sal. The influence of P. falcataria growth cannot be studied because the growth and development of a species is determined by genetic factors $(G)$, environmental factors $(E)$, and interactions between environmental and genetic factors $(G+E)$. The objects of studies is the effect of plant age and altitude of the growing place against the dimension of P.falcataria and obtain the age of plant and altitude that produce the best tree dimension. The research method used experiments using Split Plot with two factors. The main plot factor is the height of the P. falcataria growing site. Results of studies were an interaction between the heights of the place with the age of P.falcaria plants against the volume of P. falcataria. The interaction of the total height and diameter based on the altitude of $825 \mathrm{~m}$ sal and the age of P. Falcatia 9 years produced the highest volume of P. falcataria with age of 7 years.
\end{abstract}

Keywords: Paraserianthes falcataria, altitude, age

\section{PENDAHULUAN}

\section{Latar Belakang}

Kebutuhan kayu di Indonesia baik kayu pertukangan, pulp, paper maupun bahan baku industri lainnya terus meningkat seiring dengan terus bertambahnya jumlah penduduk. Peningkatan kebutuhan ini harus diimbangi dengan tersedianya produksi kayu melalui pembangunan hutan tanaman yang produktif. Pembangunan hutan tanaman yang berkembang diantaranya adalah Hutan 
Tanaman Industri di luar Jawa dan hutan rakyat di Jawa. Berdasarkan Undangundang No. 41 Tahun 1999, hutan rakyat diartikan sebagai hutan yang tumbuh di atas tanah yang dibebani hak milik dan memiliki luasan minimal 0,25 Ha. 
Keberadaan hutan rakyat menurut Darusman (2006), telah ada dan telah diusahakan sejak puluhan tahun yang lalu. Hutan rakyat memberikan manfaat pada aspek ekonomi, ekologi maupun sosial masyarakat. Walaupun perannya begitu besar, pada awalnya keberadaan dan peran hutan rakyat tidak dianggap penting, sebelum terungkap fakta dari hasil penelitian pada tahun 1976 yang dilakukan oleh Institut Pertanian Bogor (IPB) dan Universitas Gajah Mada (1977) tentang konsumsi kayu pertukangan dan kayu bakar di Pulau Jawa yang sebagian besar disediakan oleh hutan rakyat. Saat ini, usaha hutan rakyat terus berkembang mengikuti semakin besarnya permintaan pasar dan sejalan dengan pertumbuhan industri pengolah kayu di setiap kabupaten dan provinsi (Hardjanto dkk, 2012).

Usaha hutan rakyat ini sebagian besar membudidayakan jenis cepat tumbuh (fast growing species). Hal tersebut dikarenakan spesies cepat tumbuh memiliki daur yang relative pendek sehingga hasil hutan rakyat dapat segera dipanen dalam jangka waktu kurang dari sepuluh tahun. Selain itu, kriteria jenis tanaman yang banyak dibudidayakan pada lahan hutan rakyat yaitu tanaman yang pemeliharaannya mudah, relatif resisten terhadap serangan hama dan penyakit, serta memiliki nilai ekonomis tinggi. Mayoritas jenis tanaman hutan yang dibudidayakan pada hutan rakyat adalah jenis tanaman sengon dan jati (Rimbawanto, 2008). Kayu sengon dengan beragam kegunaanya menjadi salah satu tumpuan sumber bahan baku industri terutama di Pulau Jawa. Kayu sengon di Pulau Jawa umumnya berasal dari hutan rakyat. Data suplai kayu domestik Indonesia sebesar 42,3 juta $\mathrm{m}^{3}$ dimana hutan rakyat menyumbang 10 juta $\mathrm{m}^{3}$ (Kemenhut, 2010).

Pada kondisi optimum riap diameter mencapai 5 -7 $\mathrm{cm}$ per tahun (Satjapraja dan Tim Perhimpi, 1989). Menurut Atmosuseno (1994), berdasarkan catatan sejarah sengon merupakan spesies asli dari kepulauan timur Indonesia yakni Maluku dan Papua. Spesies ini baik digunakan/dimanfaatkan sebagai bubur kertas (NAS, 1979), selain itu juga dapat digunakan sebagai papan partikel, veneer, plywood serta produk komposit (CABI, 2000). Sengon juga cocok untuk dijadikan produk seperti sepatu kayu, instrumen musik, mainan anak-anak (Peh dan Khoo, 1984). Dari segi kualitas, kayu sengon termasuk kayu ringan dengan berat jenis antara 0,33 - 0,49; kelas awet IV/V dan kelas kuat IV- V). Secara ekologis, tanaman ini dapat meningkatkan kesuburan tanah karena pada akar sengon terdapat bintil akar (rhizobium) yang berperan dalam menangkap nitrogen bebas melalui proses nitrifikasi sehingga meningkatkan kandungan nitrogen 
dalam tanah. Selain batang dan akar, daun sengon (Paraserianthes falcataria) juga dimanfaatkan sebagai pakan ternak (Siregar dkk, 2008).

Sengon dapat tumbuh mulai dari pantai sampai 1600 mdpl (Hidayat, 2002). Namun secara spesifik sejauhmana pengaruh berbagai ketinggian tempat tumbuh terhadap produktifitas sengon (Paraserianthes falcataria) belum diteliti karena pertumbuhan dan perkembangan suatu spesies ditentukan oleh faktor genetik $(\mathrm{G})$, faktor lingkungan $(\mathrm{E})$, dan interaksi anatara factor lingkungan dan genetik $(\mathrm{G}+\mathrm{E})$. Ketinggian tempat merupakan salah satu faktor pengendali iklim yang berpengaruh kuat terhadap suhu udara. Suhu udara berpengaruh terhadap kecepatan metabolisme terutama fotosintesis dan respirasi tanaman. Pada suhu lingkungan lebih rendah daripada suhu dasar maka pertumbuhan tanaman berhenti (dorman), sedangkan apabila suhu lingkungan lebih tinggi dari pada suhu maksimum maka tanaman akan mati (letal). Dari aspek hubungan iklim-tanaman dikenal suhu kardinal meliputi kisaran kesesuaian suhu minimum, optimum dan maksimum untuk pertumbuhan dan perkembangan tanaman. Kisaran toleransi terhadap suhu yang berbeda tiap kultivar (sub sub spesies) menyebabkan kisaran toleransi terhadap ketinggian tempat yang berbeda-beda pula untuk tiap jenis kultivar (Nasir, 2003). Oleh karena itu, perbedaan ketinggian tempat tumbuh sengon perlu dikaji terutama pengaruhnya terhadap volume kayu yang dihasilkan dan kesehatan pohon karena kedua parameter tersebut sangat menentukan nilai ekonomis kayu sengon (produk hutan rakyat). Penelitian ini bertujuan mempelajari pengaruh umur tanaman dan ketinggian tempat tumbuh terhadap dimensi pohon sengon dan memperoleh umur tanaman dan ketinggian yang menghasilkan dimensi pohon terbaik.

\section{METODOLOGI PENELITIAN}

Survei kondisi ekologi dilaksanakan pada ditegakan hutan rakyat di Kabupaten Garut dan Cianjur. Waktu survei dilaksanakan selama 2 bulan mulai bulan November sampai Desember 2016. Objek penelitian adalah tegakan sengon. Alat yang digunakan adalah : phi band, meteran, kompas, tambang ukur, tally sheet, peta lokasi, alat-alat tulis, dan kamera.

Metode Pengumpulan Data dilakukan dengan tahapan-tahapan sebagai berikut :

\section{Rancangan Percobaan}

Percobaan menggunakan Split Plot dengan dua faktor. Faktor petak utama adalah ketinggian tempat tumbuh sengon, yaitu : 


$$
\begin{aligned}
& \mathrm{K}_{1}=125 \mathrm{mdpl} \\
& \mathrm{K}_{2}=375 \mathrm{mdpl} \\
& \mathrm{K}_{3}=625 \mathrm{mdpl} \\
& \mathrm{K}_{4}=825 \mathrm{mdpl}
\end{aligned}
$$

Faktor anak petak adalah umur sengon, yaitu:

$\mathrm{U}_{1}=1$ Tahun

$\mathrm{U}_{2}=3$ Tahun

$\mathrm{U}_{3}=5$ Tahun

$\mathrm{U}_{4}=7$ Tahun

$\mathrm{U}_{5}=9$ Tahun

\section{Operasionalisasi Variabel}

Variabel dalam penelitian ini terdiri atas variabel bebas (Independent Variable) dan variabel terikat (Dependent Variable). Variabel bebas terdiri dari tiga ketinggian tempat tumbuh pohon sengon dan umur sengon.

Variabel terikat adalah kualitas dan kuantitas pohon. Variabel terikat adalah respon volume dan kesehatan pohon akibat perlakuan ketinggian tempat dan umur pohon sengon yang berbeda teridiri atas respon utama dan respon penunjang.

a) Ketinggian tempat (m dpl). Ketinggian tempat ditentukan melalui pengukuran dengan menggunakan alat GPS (Global Positioning System).

b) Umur pohon dihitung berdasarkan tahun tanam sehingga diperoleh informasi umur pohon.

\section{Sumber dan Cara Penentuan Data}

Sumber data dalam penelitian berupa data primer dan data sekunder. Data primer merupakan data hasil observasi pada objek penelitian hasil pengamatan langsung. Pengambilan data primer dilakukan dengan cara pengambilan contoh (sampling) pada tegakan sengon pada berbagai ketinggian dan berbagai umur. Data sekunder merupakan hasil kajian pustaka dari bahan pustaka yang relevan dengan masalah yang diteliti.

\section{Teknik Pengumpulan Data}

Teknik pengumpulan data yang digunakan untuk memperoleh data yang berhubungan dengan masalah yang diteliti adalah : 
1. Data sekunder yaitu mengenai koleksi tanaman sengon hutan rakyat Kelompok Tani Wana Asri dan Citra Lestari Kabupaten Garut : Data umur pohon, ketinggian tempat/lokasi, data jenis tanah.

2. Data primer adalah volume pohon dan kesehatan pohon.

Pengambilan data primer dilakukan dengan cara sebagai berikut :

a. Intensitas pengambilan contoh

Pengambilan contoh dilakukan dua titik (plot) dengan ukuran $0,1 \mathrm{Ha}$ pada setiap ketinggian yang mewakili sebaran umur.

b. Penentuan lokasi pengambilan contoh

Lokasi pengambilan contoh dengan dibedakan berdasarkan ketinggian tempat tumbuh yang dibagi menjadi empat lokasi yaitu :

Tabel 1. Penentuan Lokasi Pengambilan Contoh

\begin{tabular}{ccc}
\hline No & Lokasi & Ketinggian $(\mathbf{m ~ d p l})$ \\
\hline 1. & I & 125 \\
2. & II & 375 \\
3. & III & 625 \\
4 & IV & 825
\end{tabular}

\section{Rancangan Analisis dan Uji Hipotesis}

Untuk melihat seberapa besar pengaruh ketinggian tempat dan umur terhadap volume dan kesehatan pohon maka diajukan model rancangan split plot dengan dua factor sebagai berikut :

Model linier bagi percobaan 2 faktor dalam rancangan Split plot adalah

$Y i j k=u+\rho k+\alpha i+\delta i k+\beta j+(\alpha \beta) i j+\varepsilon i j k$, sedangkan

Yijk = nilai pengamatan pada taraf ke-i faktor A, taraf ke-j faktor dan ulangan ke$\mathrm{k}$

$\mathrm{u}=$ rata-rata umum

$\rho \mathrm{k}=$ pengaruh kelompok ke-k

$\alpha \mathrm{i}=$ pengaruh taraf ke-I faktor A (pengaruh mainplot)

dik = pengaruh acak (a)

$\beta \mathrm{j}=$ pengaruh taraf ke- $\mathrm{j}$ faktor $\mathrm{B}$ (pengaruh sub-plot)

$\alpha \beta i j=$ pengaruh interaks taraf ke-I faktor $A$ dan taraf je-j faktor $B$

eijk = pengaruh acak $(b)$ 
Penentuan kesehatan pohon dilakukan dengan cara mengidentifikasi jenis hama dan jenis penyakit pada pohon sengon yang diteliti. Untuk menguji hipotesis diajukan hipotesis sebagai berikut :

$\mathrm{H}_{0}: \mu_{1}=\mu_{2}=\mu_{3}$

$\mathrm{H}_{1}: \mu_{1} \neq \mu_{2} \neq \mu_{3}$ atau paling sedikit ada sepasang perlakuan yang berbeda.

Kaidah keputusan apabila hasil uji menunjukan adanya keragaman respon maka $\mathrm{H}_{0}$ ditolak dan $\mathrm{H}_{1}$ diterima atau ada pengaruh dari perlakuan terhadap respon yang diamati, dalam hal ini maka hipotesis yang diajukan dalam penelitian ini diterima atau diuji.

Tabel 2. Analisis sidik ragam rancangan split plot dengan dua faktor

\begin{tabular}{lllll}
\hline $\begin{array}{l}\text { Sumber } \\
\text { keragaman }\end{array}$ & $\begin{array}{l}\text { Derajat } \\
\text { bebas }\end{array}$ & $\begin{array}{l}\text { Jumlah } \\
\text { Kuadrat }\end{array}$ & $\begin{array}{l}\text { Kuadrat } \\
\text { tengah }\end{array}$ & F-hitung \\
\hline Blok/Kelompok & r-1 & JKK & KTK & KTK/KTGa \\
Faktor A & a-1 & JKA & KTA & KTA/KTGa \\
Galat (a) & $(a-1)(r-1)$ & JKGa & KTGa & \\
Faktor B & b-1 & JKB & KTB & KTB/KTGb \\
Galat (b) & $($ b-1)(r-1) & JKGb & KTGb & \\
Interaksi A x B & $(a-1)(b-1)$ & JKAB & KTAB & KTAB/KTGc \\
Galat (c) & $(a-1)(b-1)(r-1)$ & JKGc & KTGc & \\
Total & abr-1 & JKT & & \\
\hline
\end{tabular}

Apabila hasil analisis sidik ragam menunjukan perlakuan memberikan pengaruh yang berbeda maka dilakukan uji lanjut. Pada Tabel 3 disajikan tabel uji lanjut LSD (Least Significance Different).

Tabel 3. Tabel uji lanjut LSD

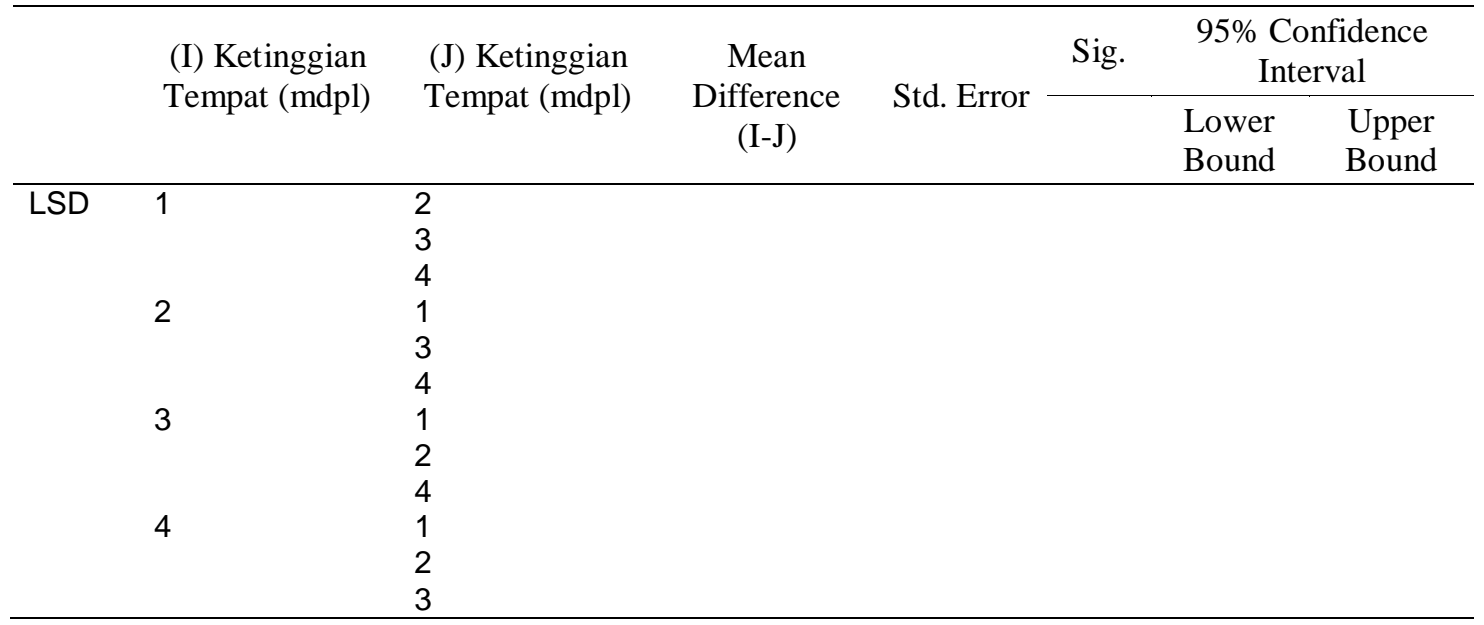




\section{HASIL DAN PEMBAHASAN}

\section{Pengaruh Umur Tanaman dan Ketinggian Tempat Tumbuh terhadap Dimensi Pohon Sengon}

Pengaruh umur tanaman pohon sengon terhadap volume kayu, maka dibuat kurva pertumbuhan diameter. Kurva pertumbuhan diameter tanaman atau tegakan yang menggambarkan pertumbuhan tanaman atau pohon ditinjau dari aspek perkembangan dimensi diameter dan tinggi pohon-pohon dalam tegakan mulai dari tumbuh, ditanam hingga mencapai dewasa (Bruce dan Schumacher, 1950). Pengamatan dilakukan di dua tempat tumbuh yang berbeda, yaitu di Kabupaten Garut dan Kabupaten Cianjur. Kedua daerah ini merupakan salah satu daerah yang mana masyarakatnya banyak membudidayakan sengon.

\section{Tinggi Total}

Tinggi total merupakan selisih tinggi antara ujung pertumbuhan atas (pucuk) dengan pangkal pohon. Tinggi pohon dihasilkan dari pertumbuhan primer sebagai hasil dari aktifitas sel meristem yang terdapat pada ujung-ujung pertumbuhan. Tinggi total dijadikan salah satu acuan dalam perniagaan kayu karena tinggi total merupakan salah satu indikator penentu dimensi pohon. Selain itu, tinggi total juga menjadi penting mengingat beberapa penggunaan kayu sengon mengharuskan tinggi total/panjang kayu yang tinggi, seperti untuk penggunaan kaso dan papan.

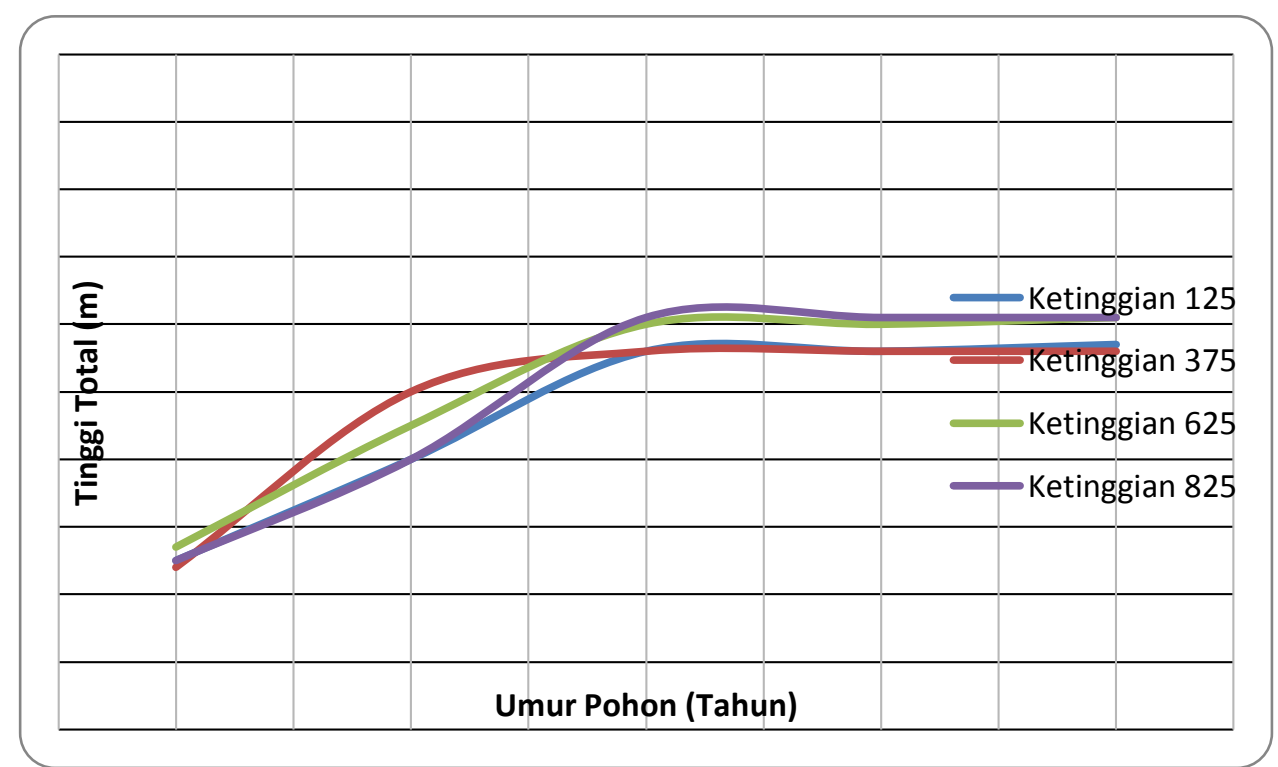

Gambar 1. Laju Pertambahan Tinggi Total pada Berbagai Umur dan Ketinggian Tempat di Kabupaten Garut 
Pengamatan karakter tinggi total pada ketinggian tempat $125 \mathrm{mdpl}, 375$ mdpl, 6225 m dpl, dan 825 m dpl di Kabupaten Garut (Gambar 1) dan Kabupaten Cianjur (Gambar 2) menujukan trend yang meningkat seiring dengan pertambahan umur. Pertambahan tinggi sangat cepat mulai dari umur satu sampai lima tahun. Namun, pertambahan tinggi mulai melambat dari umur lima sampai dengan sembilan tahun.

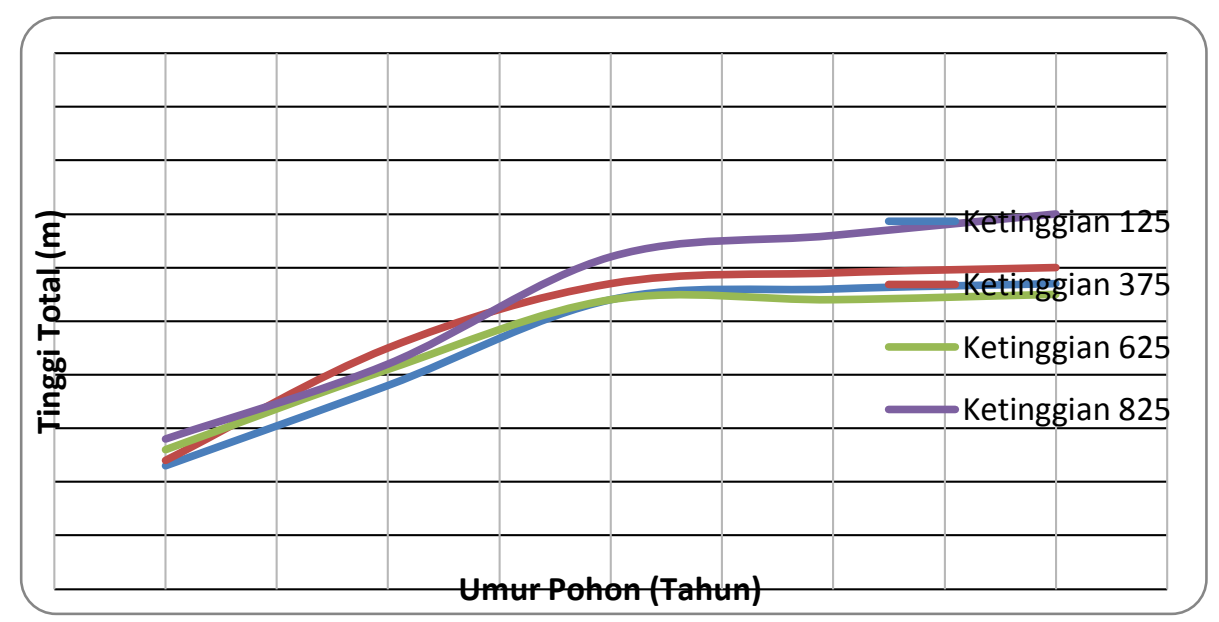

Gambar 2. Laju Pertambahan Tinggi Total pada Berbagai Umur dan Ketinggian Tempat di Kabupaten Cianjur

\section{Diameter}

Karakter diameter pohon merupakan hasil pertumbuhan sekunder yaitu pertumbuhan ke samping sebagai akibat dari aktifitas kambium dalam kayu. Diameter menjadi salah satu faktor penentu nilai jual karena karakter diameter berpengaruh terhadap volume kayu yang dihasilkan. Berikut ini adalah data pertambahan diameter sengon pada berbagai ketinggian tempat di Kabupaten Garut yang disajikan pada Gambar 3. 


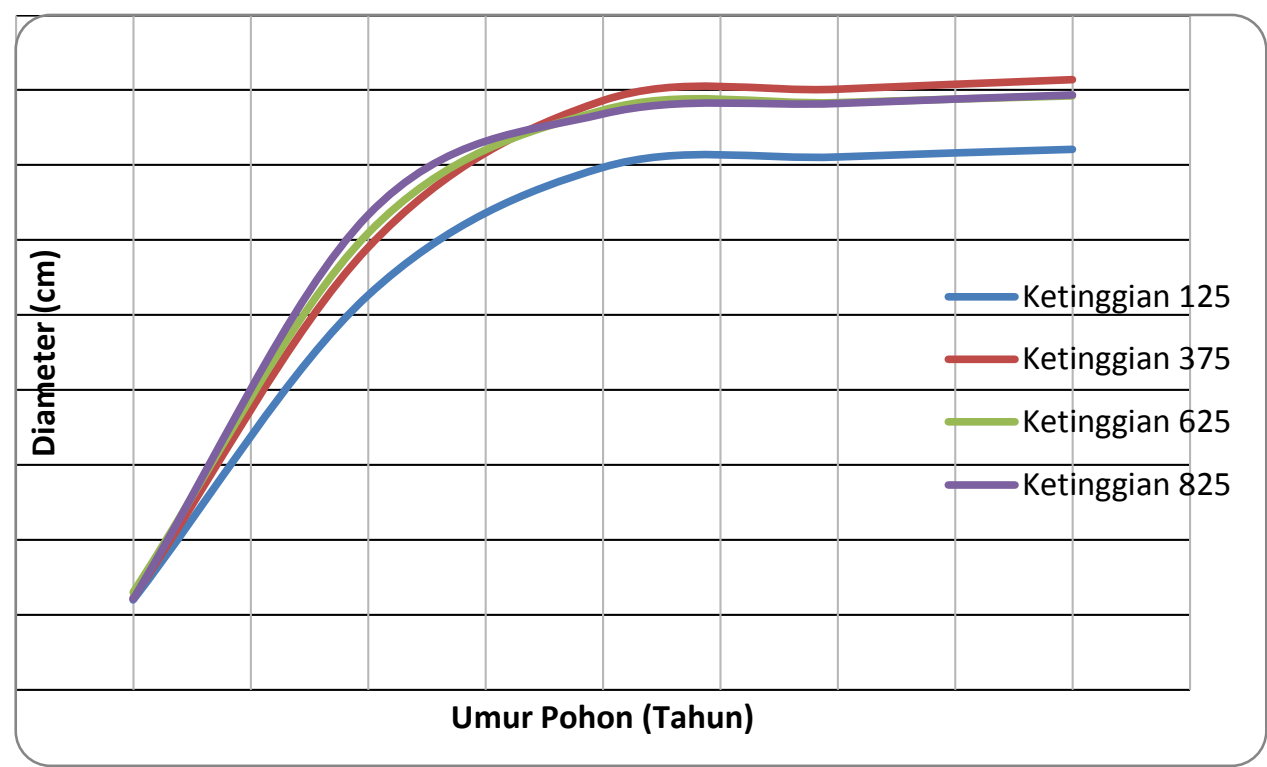

Gambar 3. Laju Pertambahan Diameter pada Berbagai Umur dan Ketinggian Tempat di Kabupaten Garut

Gambar 3. Menunjukkan bahwa laju pertambahan diameter sengon semakin meningkat seiring dengan pertambahan umur. Laju pertambahan diameter ini relatif seragam pada setiap ketinggian, yaitu meningkat seiring dengan pertambahan umur. Trend ini juga terjadi di Kabupaten Cianjur yang dapat dilihat pada Gambar 4.

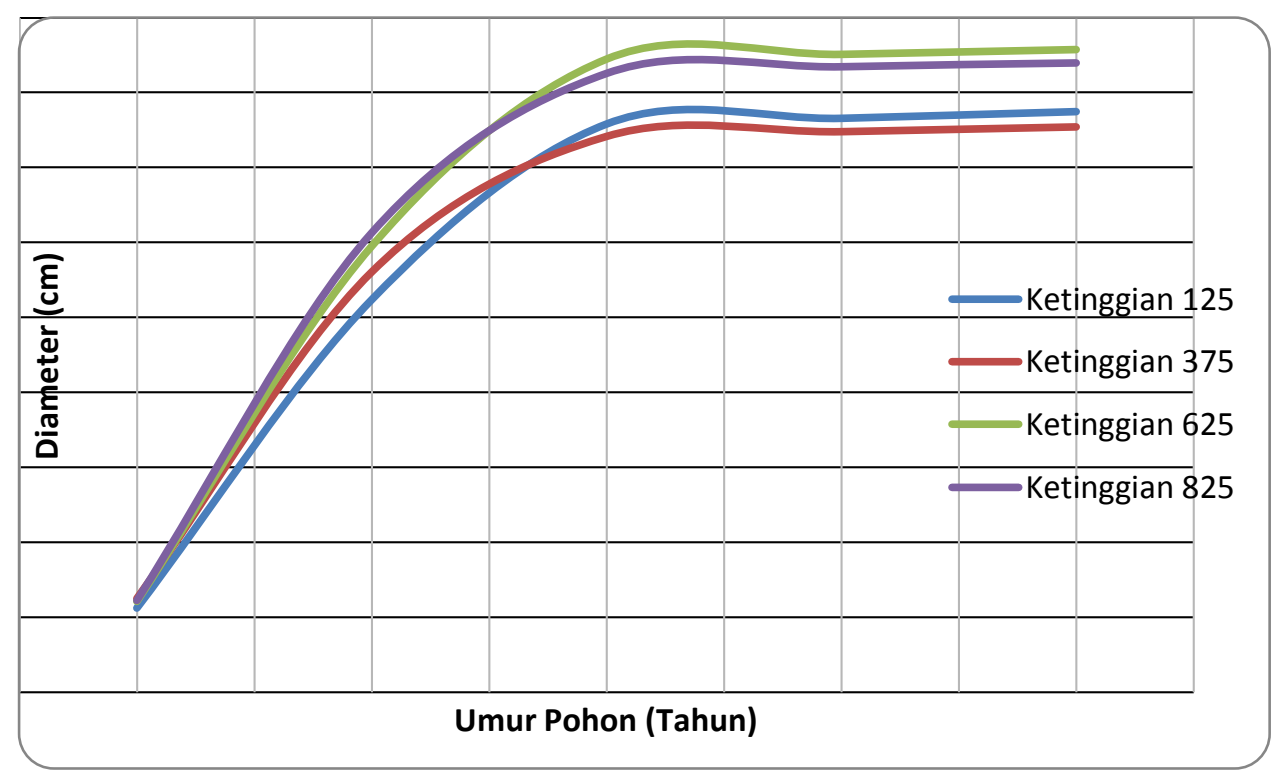

Gambar 4. Laju Pertambahan Diameter pada Berbagai Umur dan Ketinggian Tempat di Kabupaten Cianjur 


\section{Volume}

Volume diperoleh dari tinggi dan diameter pohon. Volume pohon sengon merupakan salah satu parameter yang menentukan nilai jual kayu. Aspek kubikasi kayu (volume) merupakan salah satu indikator keberhasilan petani sengon karena pendapatannya ditentukan oleh besarnya kubikasi.

Volume pohon sengon di Kabupaten Garut dan Kabupaten Cianjur padda berbagai ketinggian tempat pertambahannya mengikuti trend pada diameter dan tinggi pohon. Hal ini dikarenakan tinggi total dan diameter merupakan faktor penentu volume pohon. Gambaran pertambahan volume pohon di Kabupaten Garut disajikan pada Gambar 5. Laju pertambahan volume pohon di Kabupaten Cianjur disajikan pada Gambar 6.

Berdasarkan data volume dari tegakan sengon umur 1-9 tahun maka dapat terlihat bahwa tanaman sengon mempunyai trend pertumbuhan sejalan dengan bertambahnya umur. Hal ini sesuai dengan pernyataan Daniel et al. (1987), bahwa pertumbuhan merupakan fungsi dari umur tegakan yang sifatnya tergantung pada jenis dan kualitas tempat tumbuh. Pada umur 0-5 tahun derajat kemiringan kurva sangat tajam, sedangkan setelah umur 5 tahun derajat kemiringan kurva semakin melandai. Hal ini mengindikasikan bahwa pada umur 0-5 tahun terjadi pertumbuhan diameter yang sangat pesat pada tanaman sengon. Setelah lepas 5 tahun, tanaman sengon masih mengalami pertumbuhan diameter namun tidak sebesar pada umur 0-5 tahun. Trend pertumbuhan tanaman sengon di Kediri hampir sama dengan trend pertumbuhan sengon di Benakat. Sebagaimana hasil pengamatan oleh Riyanto dan Kusnandar (1992) di Benakat, pertumbuhan diameter sengon maksimal adalah pada saat mencapai umur 5 tahun.

Laju pertumbuhan optimum tercapai pada saat tegakan berumur 2 (dua) tahun dan 3 (tiga) tahun.Laju pertumbuhan akan semakin menurun mendekati nol seiring dengan pertambahan umur tegakan. Kurva ini dapat untuk dijadikan acuan dalam pengelolaan yang berkaitan dengan pengaplikasian praktek teknik silvikultur. Dengan melihat grafik laju pertumbuhan diatas dapat diketahui bahwa pada umur 2 tahun dan 3 tahun merupakan masa muda dari tanaman sengon dimana pertumbuhan optimum terjadi. Pada masa ini tanaman membutuhkan suplai makanan yang terbanyak dan terbaik dari segi kuantitas dan kualitas. Sehingga masa-masa ini merupakan masa yang tepat untuk mengaplikasikan praktek silvikultur, misalnya pemupukan, pembersihan dari gulma, dan sebagainya Jadi perlakuan silvikultur yang baik dan tepat sangat diperlukan pada umur tersebut. 

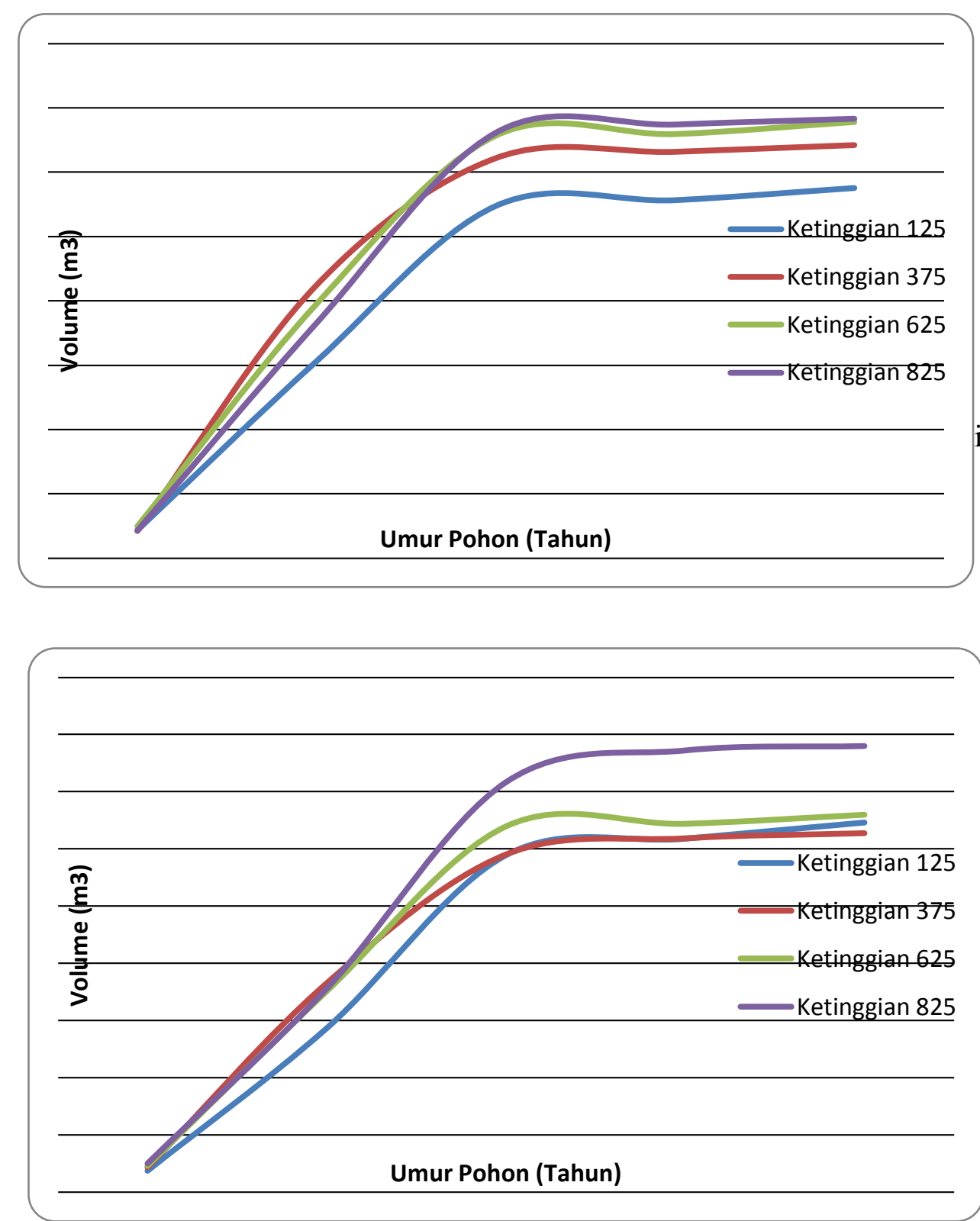

Gambar 6. Laju Pertambahan Volume pada Berbagai Umur dan Ketinggian Tempat di Kabupaten Cianjur

Trend peningkatan volume pohon pada berbagai ketinggian tempat dan tempat tumbuh tersebut perlu diuji secara statistik. Hasil uji statistik volume pohon sengon pada berbagai ketinggian tempat dan tempat tumbuh disajikan pada Tabel 2. Berdasarkan tabel annova (Tabel 2) terlihat bahwa faktor ketinggian tempat dan umur pohon memberikan pengaruh yang sangat signifikan atau sangat berbeda nyata terhadap volume pohon. Hal ini menunjukan bahwa dari berbagai 
ketinggian tempat sengon tumbuh memberikan pengaruh yang berbeda terhadap volume pohon.

Tabel 2. Hasil uji statistik volume sengon pada berbagai ketinggian tempat dan tempat tumbuh

\begin{tabular}{llrrrrr}
\hline \multicolumn{2}{c}{ Source } & $\begin{array}{c}\text { Type III Sum } \\
\text { of Squares }\end{array}$ & df & Mean Square & F & Sig. \\
\hline Intercept & Hypothesis & 218,697 & 1 & 218,697 & 15,232 &, 017 \\
& Error & 57,431 & 4 & $14,358(\mathrm{a})$ & & \\
ketinggian_tempat & Hypothesis & 1,063 & 3 &, 354 & 12,202 &, 000 \\
& Error &, 813 & 28 &, $029(\mathrm{~b})$ & & \\
tempat_tumbuh & Hypothesis &, 022 & 1 &, 022 &, 745 &, 395 \\
& Error &, 813 & 28 &, $029(\mathrm{~b})$ & & \\
Kelompok & Hypothesis & 57,431 & 4 & 14,358 & 494,516 &, 000 \\
& Error &, 813 & 28 &, $029(\mathrm{~b})$ & & \\
ketinggian_tempat $*$ & Hypothesis &, 251 & 3 &, 084 & 2,877 &, 054 \\
tempat_tumbuh & Error &, 813 & 28 &, $029(\mathrm{~b})$ & & \\
\hline
\end{tabular}

Tabel 3. Hasil Uji Lanjut Berbagai Ketinggian Tempat pada Volume Pohon

\begin{tabular}{|c|c|c|c|c|c|c|c|}
\hline & \multirow{2}{*}{$\begin{array}{l}\text { (I) } \\
\text { Ketinggian } \\
\text { Tempat } \\
\text { (mdpl) }\end{array}$} & \multirow{2}{*}{$\begin{array}{l}(\mathrm{J}) \\
\text { Ketinggian } \\
\text { Tempat } \\
(\mathrm{mdpl})\end{array}$} & \multirow[b]{2}{*}{$\begin{array}{c}\text { Mean } \\
\text { Difference } \\
\text { (I-J) }\end{array}$} & \multirow{2}{*}{$\begin{array}{l}\text { Std. } \\
\text { Error }\end{array}$} & \multirow{2}{*}{ Sig. } & \multicolumn{2}{|c|}{$\begin{array}{l}\text { 95\% Confidence } \\
\text { Interval }\end{array}$} \\
\hline & & & & & & $\begin{array}{l}\text { Lower } \\
\text { Bound }\end{array}$ & $\begin{array}{l}\text { Upper } \\
\text { Bound }\end{array}$ \\
\hline \multirow[t]{12}{*}{ LSD } & 1 & 2 &,$- 2010(*)$ & .07620 & 013 &,- 3571 &,- 0449 \\
\hline & & 3 &,$- 2880(*)$ & ,07620 & ,001 &,- 4441 &,- 1319 \\
\hline & & 4 &,$- 4520(*)$ & ,07620 &, 000 &,- 6081 &,- 2959 \\
\hline & 2 & 1 &, $2010(*)$ & ,07620 & ,013 & ,0449 & ,3571 \\
\hline & & 3 &,- 0870 &, 07620 & 263 &,- 2431 &, 0691 \\
\hline & & 4 &,$- 2510(*)$ & ,07620 & ,003 &,- 4071 &,- 0949 \\
\hline & 3 & 1 &, $2880(*)$ & ,07620 & ,001 & ,1319 & ,4441 \\
\hline & & 2 &, 0870 & 07620 & ,263 &,- 0691 & 2431 \\
\hline & & 4 &,$- 1640(*)$ & ,07620 & 040 &,- 3201 &,- 0079 \\
\hline & 4 & 1 &, $4520(*)$ & 07620 & ,000 & 2959 & ,6081 \\
\hline & & 2 &, $2510(*)$ & 07620 & 003 & 0949 & ,4071 \\
\hline & & 3 & $1640(*)$ & 07620 & 040 & 0079 &, 3201 \\
\hline
\end{tabular}

Hasil uji lanjut mengenai pengaruh berbagai ketinggian tempat terhadap volume pohon sengon disajikan pada tabel 3 uji lanjut menunjukan bahwa ketinggian tempat 825 mdpl memberikan pengaruh yang terbaik pada volume pohon. Hal ini berarti pohon sengon yang tumbuh pada ketinggian 825 mdpl pada umur yang sama memiliki volume yang lebih besar dibandingkan sengon yang tumbuh pada ketinggian $125 \mathrm{mdpl}, 375 \mathrm{mdpl}$, dan $625 \mathrm{mdpl}$. 
Volume pohon sengon yang ditanam pada ketinggian tempat $375 \mathrm{mdpl}$ dan 625 mdpl memberikan respon yang sama, namun apabila dibandingkan dengan sengon pada ketinggian $125 \mathrm{mdpl}$ volumenya berbeda. Secara statistik terlihat dari subsite yang sama namun secara aktual dapat dikatakan bahwa pertumbuhan sengon yang ditanam pada ketinggial 375 mdpl dan 625 mdpl memiliki volume yang relatif seragam.

Faktor umur pohon juga memberikan pengaruh yang sangat berbeda nyata terhadap volume pohon, pertambahan umur cenderung akan menambah volume pohon karena terjadi proses pertumbuhan baik pertambahan jumlah sel, volume sel, maupun masa sel. Pertumbuhan pada pohon ada dua jenis yaitu pertumbuhan sekunder (ke samping) yaitu pertambahan diameter dan pertumbuhan primer (ke atas). Dari pertumbuhan sekunder dan primer ini dihasilkan volume kayu, sehingga dengan pertambahan umur pohon akan menambah kubikasi (volume) kayu. Pertumbuhan pohon akan terus meningkat sampai dengan pertumbuhan optimum, yang mana biasa disebut dengan istilah daur tebang.

\section{KESIMPULAN DAN SARAN}

Terjadi interaksi antara ketinggian tempat dengan umur tanaman sengon terhadap volume sengon. Interaksi terhadap tinggi total dan diameter berdasarkan ketinggian 825 mdpl dan umur sengon 9 tahun mengasilkan volume sengon yang tertinggi dengan umur 7 tahun.

\section{DAFTAR PUSTAKA}

Atmosuseno BS. 1994. Budidaya, kegunaan, dan prospek sengon. Jakarta: Penebar Swadaya, Jakarta.

Buckman, HO., dan N.C. Brady. 1982. Ilmu Tanah. BharataKaryaAksara. Jakarta. 788 hal.

CABI. 2000. The forestry compendium: a silviculture reference. Module 1.Commonwealth Agricultural Bureau International, Wallingford

Charomaini, M. dan Suhaendi, H. 1997 Genetic variation of Paraserianthes falcataria seed sources in Indonesia and its potential in tree breeding programs. Dalam: Zabala, N. (ed.) Workshop international tentang spesies Albizia dan Paraserianthes , 151-156. Prosiding workshop, 13-19 November 1994, Bislig, Surigao del Sur, Filipina. Forest, Farm, and Community Tree Research Reports (tema khusus). Winrock International, Morrilton, Arkansas, AS. 
Daniel, T. W dkk. 1992. Prinsip - prinsip Silvikultur. Gajahmada University Press.Yogyakarta.650 hal.

Dalya nurdin. 2014. Analisis Finansial Pembangunan Hutan Rakyat. Tesis. Program Pascasarjana Universitas Hasanudin. Makasar.

Darusman, Dudung dan Hardjanto. 2006. Tinjauan Ekonomi Hutan Rakyat. Dalam Kontribusi Hutan Rakyat. Dalam Kesinambungan Industri Kehutanan. Prosiding Seminar Hasil Litbang Hasil Hutan. Bogor : Kementerian Lingkungan Hidup Dan Kehutanan. Halaman : 4-13.

Gardner F.P., Pearce R.B, dan Mitchell R.L. 1991. Fisiologi Tanaman Budidaya. UI-Press. Jakarta. 428 hal.

Hanafiah, K.A. 2005. Dasar-dasar Ilmu Tanah. PT Raja Grafindo Persada. Jakarta. 360 hal.

Hardjanto dkk, 2012. Desain Kelembagaan Usaha Hutan Rakyat untuk Mewujudkan Kelestarian Hutan dan Kelestarian Usaha dalam Upaya Pengentasan Kemiskinan Masyarakat Pedesaan. Jurnal Ilmu Pertanian Indonesia (JIPI), Agustus 2012. Vol. 17 (2): 103 107. ISSN $0853 \pm 4217$

Hidayat, J., 2002. Informasi Singkat Benih Paraserianthes falcataria (L) Nielsen. No 23, Juni 2002. Direktorat Perbenihan Tanaman Hutan : Jakarta.

Kurinobu, S., Daryono, P., Naiem, M. dan Matsune, K. 2007a A provisional growth model with a size-density relationship for a plantation of Paraserianthes falcataria derived from measurements taken over 2 years in Pare, Indonesia. Journal of Forest Research 12: 230-236.

Martawijaya, A. Kartasujana, I., Mandang, Y.I., Prawira, S.A. dan Kadir, K. 1989 Atlas Kayu Indonesia Jilid II. Pusat Penelitian dan Pengembangan Hasil Hutan, Bogor, Indonesia.

Nasir, A. 2003.Pengaruh cuaca dan iklim terhadap tanaman. Pelatihan Dosen PT Se Jawa-Bali dalam Bidang Pemodelan dan Simulasi Komputer untuk Pertanian di Bogor pada tanggal 4 - 16 Agustus 2003. Bogor.

NAS .1979.Tropical legumes: resources for the future. National Academy Press, Washington, DC

Pandit IKN, Ramdhan H. 2002.AnatomiKayu :Pengantar Sifat Kayu Sebagai Bahan Baku: Bogor: Yayasan Penerbit Fakultas Kehutanan Institut Pertanian Bogor.

Rimbawanto A. 2008. Pemuliaan tanaman dan ketahanan penyakit pada sengon. Makalah Workshop Penanggulangan Serangan Karat Purupada Tanaman 
Sengon 19 Nop 008. Balai Besar Penelitian Bioteknologi dan Pemuliaan Tanaman Hutan. Yogyakarta.

Satjapraja O, Tim Perhimpi. 1989. Penilaian wilayah kesesuaian agroklimat hutan tanaman industri sengon (Albizia falcataria). Seminar sehari Peningkatan Pemanfaatan Agrometeorologi dalam Pengembangan Hutan Tanaman Industri dan Pengembangan Perkebunan. Jakarta 31 Agustus 1989.

Siregar,I. S. 2008. Kayu Sengon. Buku.Penebar Sadaya. Jakarta. 78 p

Soerianegara, I. dan Lemmens, R.H.M.J. 1993 Plant resources of South-East Asia 5(1): Timber trees: major commercial timbers. Pudoc Scientific Publishers, Wageningen, Belanda.

Sumarna, K. 1961 Tabel Tegakan Normal Sementara untuk Albizia falcataria . Pengumuman No. 77. Lembaga Penelitian Kehutanan, Bogor, Indonesia.

Suprapto edi. 2010. HUTAN RAKYAT: Aspek Produksi, Ekologi dan Kelembagaan. Lembaga ARuPA, Jogjakarta.

Tsoumis, G. 1991. Science and Technology of Wood (Structur, Properties, Utilization) Van Nostrand Reinhold. New York. 494p. 